\title{
Imaging of Pheochromocytoma and Paraganglioma
}

\author{
Jorge A. Carrasquillo ${ }^{1}$, Clara C. Chen ${ }^{2}$, Abhishek Jha ${ }^{3}$, Alexander Ling ${ }^{2}$, Frank I. Lin ${ }^{4}$, Daniel A. Pryma ${ }^{5}$, and Karel Pacak ${ }^{3}$ \\ ${ }^{1}$ Molecular Imaging and Therapy Service, Memorial Sloan Kettering Cancer Center, New York, New York; ${ }^{2}$ Department of Radiology, \\ Clinical Center, NIH, Bethesda, Maryland; ${ }^{3}$ Section on Medical Neuroendocrinology, National Institute of Child Health and Human \\ Development, NIH, Bethesda, Maryland; ${ }^{4}$ Molecular Imaging Branch, National Cancer Institute, NIH, Bethesda, Maryland; and \\ ${ }^{5}$ Department of Radiology, Hospital of the University of Pennsylvania, Philadelphia, Pennsylvania
}

\begin{abstract}
Learning Objectives: On successful completion of this activity, participants should be able to (1) identify the difference between pheochromocytoma and paraganglioma; (2) identify radiopharmaceutical agents available for imaging pheochromocytomas and extraadrenal paragangliomas; and (3) recognize the importance of genotype in selection of the imaging radiopharmaceutical for patients with pheochromocytoma or paraganglioma.
\end{abstract}

Financial Disclosure: This research was funded in part by NCI Cancer Center support grant P30CA008748 and the Eunice Kennedy Shriver National Institute of Child Health and Human Development, NIH. Dr. Pryma reports research and consulting funding from Siemens and 511 Pharma, as well as consulting funding from Bayer. The authors of this article have indicated no other relevant relationships that could be perceived as a real or apparent conflict of interest.

CME Credit: SNMMI is accredited by the Accreditation Council for Continuing Medical Education (ACCME) to sponsor continuing education for physicians. SNMMI designates each JNM continuing education article for a maximum of 2.0 AMA PRA Category 1 Credits. Physicians should claim only credit commensurate with the extent of their participation in the activity. For CE credit, SAM, and other credit types, participants can access this activity through the SNMMI website (http://www.snmmilearningcenter.org) through August 2024.

Imaging plays a critical role in the management of pheochromocytomas and paragangliomas and often guides treatment. The discovery of susceptibility genes associated with these tumors has led to better understanding of clinical and imaging phenotypes. Functional imaging is of prime importance because of its sensitivity and specificity in subtypes of pheochromocytoma and paraganglioma. Several radiopharmaceuticals have been developed to target specific receptors and metabolic processes seen in pheochromocytomas and paragangliomas, including ${ }^{131} \mathrm{I} /{ }^{123} \mathrm{I}$-metaiodobenzylguanidine, $6-{ }^{18} \mathrm{~F}$-fluoro-L-3,4-dihydroxyphenylalanine, ${ }^{18} \mathrm{~F}-\mathrm{FDG}$, and ${ }^{68} \mathrm{Ga}-\mathrm{DOTA}$-somatostatin analogs. Two of these have consequently been adapted for therapy. This educational review focuses on the current imaging approaches used in pheochromocytomas and paragangliomas, which vary among clinical and genotypic presentations.

Key Words: pheochromocytoma; paraganglioma; somatostatin; MIBG; DOTATATE; FDOPA; FDG

J Nucl Med 2021; 62:1033-1042

DOI: $10.2967 /$ jnumed.120.259689

$\mathbf{T}$ he World Health Organization defines paragangliomas as neuroendocrine tumors that originate in neural crest tissue (1). Most commonly, they arise in the adrenals and are called pheochromocytomas, whereas those outside the adrenals are called extraadrenal paragangliomas. Most parasympathetic paragangliomas arise in the head and neck (head and neck paraganglioma, or HNPGL), whereas most of sympathetic origin arise below the diaphragm. Most pheochromocytomas and paragangliomas are apparently benign, whereas 2\%-26\% develop metastases (2). Histopathology cannot differentiate between benign and malignant disease; there-

Received Nov. 2, 2020; revision accepted Feb. 16, 2021.

For correspondence or reprints, contact Jorge A. Carrasquillo (carrasj1@ mskcc.org).

COPYRIGHT (C) 2021 by the Society of Nuclear Medicine and Molecular Imaging. fore, the World Health Organization uses the term metastatic rather than malignant. Metastatic disease is defined by tumor presence in sites (e.g., lymph nodes and bones) where chromaffin cells or paraganglia are not normally present (2).

Classically, pheochromocytoma presents with hypertension, headaches, palpitations, pallor, sweating, and anxiety, whereas paraganglioma frequently presents with pain or mass effect (3). Biochemical phenotype (secretion patterns: norepinephrine, epinephrine, and dopamine and their metabolites) is reflective of genotype (4). Pheochromocytomas and paragangliomas may be biochemically silent in over $10 \%$ of cases (2), and a fraction present as incidentalomas (3).

\section{GENETICS}

Pheochromocytomas and paragangliomas are the group of tumors most frequently associated with genetic mutation. Driver mutations, fusion genes, or copy number alterations are identified in $95 \%$ of patients, with more than 20 germline or somatic gene mutations identified (5). Mutations in $S D H(A / B / C / D / A F 2)$, collectively $S D H x$, are most frequently encountered. Mutational status has implications for clinical, biochemical, and imaging phenotype. For example, VHL, RET, NF1, MAX, TMEM12, and HRAS mutations most often present with pheochromocytomas, whereas $S D H x, F H, P H D 1 / 2$, and EPASI/ $H I F 2 A$ mutations most often present with paraganglioma. Sporadic pheochromocytomas and paragangliomas often have somatic mutations in NF1, VHL, RET, and MAX (5). Three pheochromocytoma/ paraganglioma clusters have been described: cluster 1, a pseudohypoxia cluster affecting hypoxia-signaling pathway ( $S D H x, F H$, $V H L / E P A S 1$ ); cluster 2, a tyrosine kinase signaling cluster (RET, NF1, TMEM127, MAX, HRAS); and cluster 3, a Wnt signaling cluster (CSDE1, MAML3) (5). Genetic testing is now recommended for all patients with pheochromocytoma or paraganglioma.

\section{IMAGING MODALITIES}

The role of imaging in pheochromocytoma and paraganglioma includes confirming the diagnosis when biochemical results are 
positive or borderline; defining the location, extent, and optimal approach to surgery; evaluating for multifocal or metastatic disease (staging); evaluating response to treatment (restaging); performing surveillance screening for the presence or recurrence of disease; and selecting suitable patients for theranostic applications $\left({ }^{90} \mathrm{Y} /{ }^{177} \mathrm{Lu}-\mathrm{DOTA}\right.$-somatostatin analog [SSA $]$ or ${ }^{131}$ I-metaiodobenzylguanidine [MIBG] therapy). Imaging modalities include anatomic imaging - principally CT and MRI - and functional imaging that relies on physiologic processes or receptor targeting. This continuing education review focuses on imaging modalities that are currently approved or are widely available for pheochromocytoma and paraganglioma.

\section{${ }^{131} \mathrm{I} /{ }^{123} \mathrm{I}-$ MIBG}

Radiolabeled MIBG $\left({ }^{131} \mathrm{I} /{ }^{123} \mathrm{I}-\mathrm{MIBG}\right.$, iobenguane) binds to norepinephrine transporters, which are internalized and shuttled into secretory granules via vesicular monoamine transporters (6).

\section{Patient Preparation, Administration, Pharmacokinetics, Biodistribution, and Dosimetry}

Procedure guidelines for imaging pheochromocytoma or paraganglioma with ${ }^{123} \mathrm{I} /{ }^{131} \mathrm{I}$-MIBG have been published (7). Before injection, it must be established that the patient has not taken pharmaceuticals that interfere with MIBG (Supplemental Table 1; supplemental materials are available at http://jnm.snmjournals. org). Because free ${ }^{123} \mathrm{I} /{ }^{131} \mathrm{I}$ may be released, thyroid protection is performed, most commonly using a saturated solution of potassium iodide $2-24 \mathrm{~h}$ before injection of MIBG and continued for several days thereafter.

${ }^{123} \mathrm{I}-\mathrm{MIBG}$ is preferable for imaging (8), whereas ${ }^{131} \mathrm{I}-\mathrm{MIBG}$ is reserved for dosimetry before therapy or documenting posttherapy biodistribution. Administered activity and dosimetry are presented in Supplemental Table 1. After administration of MIBG, blood clearance occurs quickly, with whole-body excretion of more than

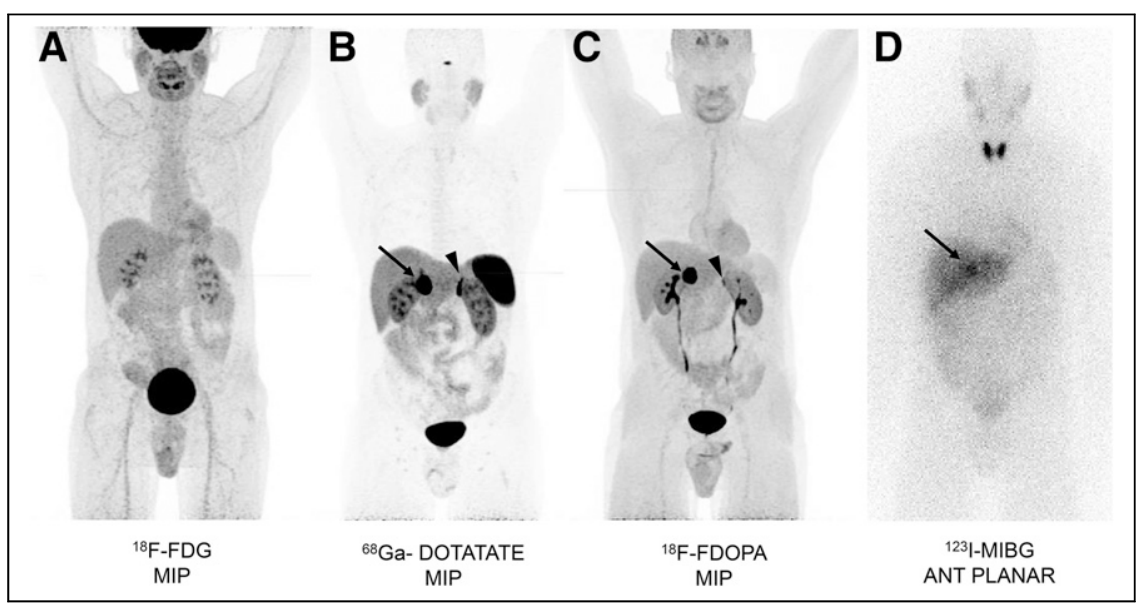

FIGURE 1. A 54-y-old man with benign sporadic right adrenal pheochromocytoma (arrows). (A) Maximum-intensity-projection (MIP) ${ }^{18}$ F-FDG PET scan (SUV $\left.\max , 3.7\right)$ showing physiologic brain uptake; urinary excretion; and mild activity in blood pool, cardiac wall, salivary glands, and gastrointestinal tract. (B) MIP ${ }^{68}$ Ga-DOTATATE PET scan (SUV $\left.\max , 75.5\right)$ showing prominent uptake in spleen, kidneys, liver, and pituitary; low-level uptake in salivary glands and thyroid; and prominent normal left adrenal (arrowhead). (C) MIP ${ }^{18} \mathrm{~F}$-FDOPA PET scan $\left(\mathrm{SUV}_{\max }, 23\right)$ showing uptake in basal ganglia; low-level uptake in esophagus and cardiac wall; normal left adrenal (arrowhead) and gastrointestinal tract; and excretion through kidneys and bladder. (D) Anterior ${ }^{123} \mathrm{I}-\mathrm{MIBG}$ planar scan at $24 \mathrm{~h}$ showing uptake in pheochromocytoma (arrow) (greater than liver level) and in thyroid, despite blockade; mild uptake in pheochromocytoma (arrow) in liver, salivary glands, and cardiac wall; and faint excretion into bladder and gastrointestinal tract.
$80 \%$ in $2-5 \mathrm{~d}$, predominantly through the kidneys (9). Normal biodistribution includes uptake in the liver, lungs, heart, spleen, and salivary glands (Fig. 1). The adrenals are often visualized, and in the is considered physiologic

\section{Clinical Results}

A metaanalysis found an ${ }^{123}$ I-MIBG sensitivity of $96 \%$ in patients nonmetastatic pheochromocytoma or paraganglioma and $79 \%$ patients with metastatic pheochromocytoma or paraganglioma Recent studies that include more cases of paraganglioma found odologic differences. Typically, ${ }^{123}$ I-MIBG sensitivity is higher for detecting pheochromocytoma than for detecting paraganglioma, at $88 \%$ and $67 \%$, respectively $(21)$. Others report sensitivity of $76 \%-92 \%$ for pheochromocytoma and $35 \%-70 \%$ for paraganglioma $(3,11,17,22,23)$. MIBG sensitivity in patients with $S D H x$ is low $(14,24)$. With newer radiopharmaceuticals, the once pivotal role of radiolabeled MIBG in pheochromocytoma/paraganglioma imaging has diminished to screening for ${ }^{131} \mathrm{I}-\mathrm{MIBG}$ therapy.

\section{${ }^{18}$ F-FDOPA}

$6{ }^{18}{ }^{8} \mathrm{~F}$-fluoro-L-3,4-dihydroxyphenylalanine $\left({ }^{18} \mathrm{~F}\right.$-FDOPA, IASOdopa; IASON $\mathrm{GmbH}$ ) is a radiolabeled amino acid developed as a er of dopamine synthesis for Parkinson disease or neuroendoand the U.S. Food and Drug Administration but limited in availability in the United States. ${ }^{18}$ F-FDOPA is transported into target cells via the large neutral amino acid transporter-1, after which it is decarboxylated to ${ }^{18} \mathrm{~F}$-fluorodopamine, which is sequestered into secretory vesicles via vesicular monoamine transporters or degraded by other enzymes.

Patient Preparation, Administration, Pharmacokinetics, Biodistribution, and Dosimetry

Procedure guidelines for ${ }^{18} \mathrm{~F}$-FDOPA have been published $(25,26)$. No medications have been reported to interfere with imaging. Carbidopa, a peripheral decarboxylation blocking agent, improves uptake in pheochromocytoma and paraganglioma (27), although its use has not been incorporated by all groups (28).

The administered activity and dosimetry are presented in Supplemental Table 1. Pharmacokinetics and biodistribution studies of ${ }^{18}$ F-FDOPA (29) show rapid blood clearance, with most tumor uptake occurring within $30 \mathrm{~min}$ of administration (27). Physiologic uptake occurs in the basal ganglia, liver, and pancreas (Fig. 1). Mild uptake is seen in the bowel and esophagus. The low 
TABLE 1

Sensitivity of Detection of Benign Pheochromocytoma and Paraganglioma ( $n \geq 20$ Patients or Prospective Studies)

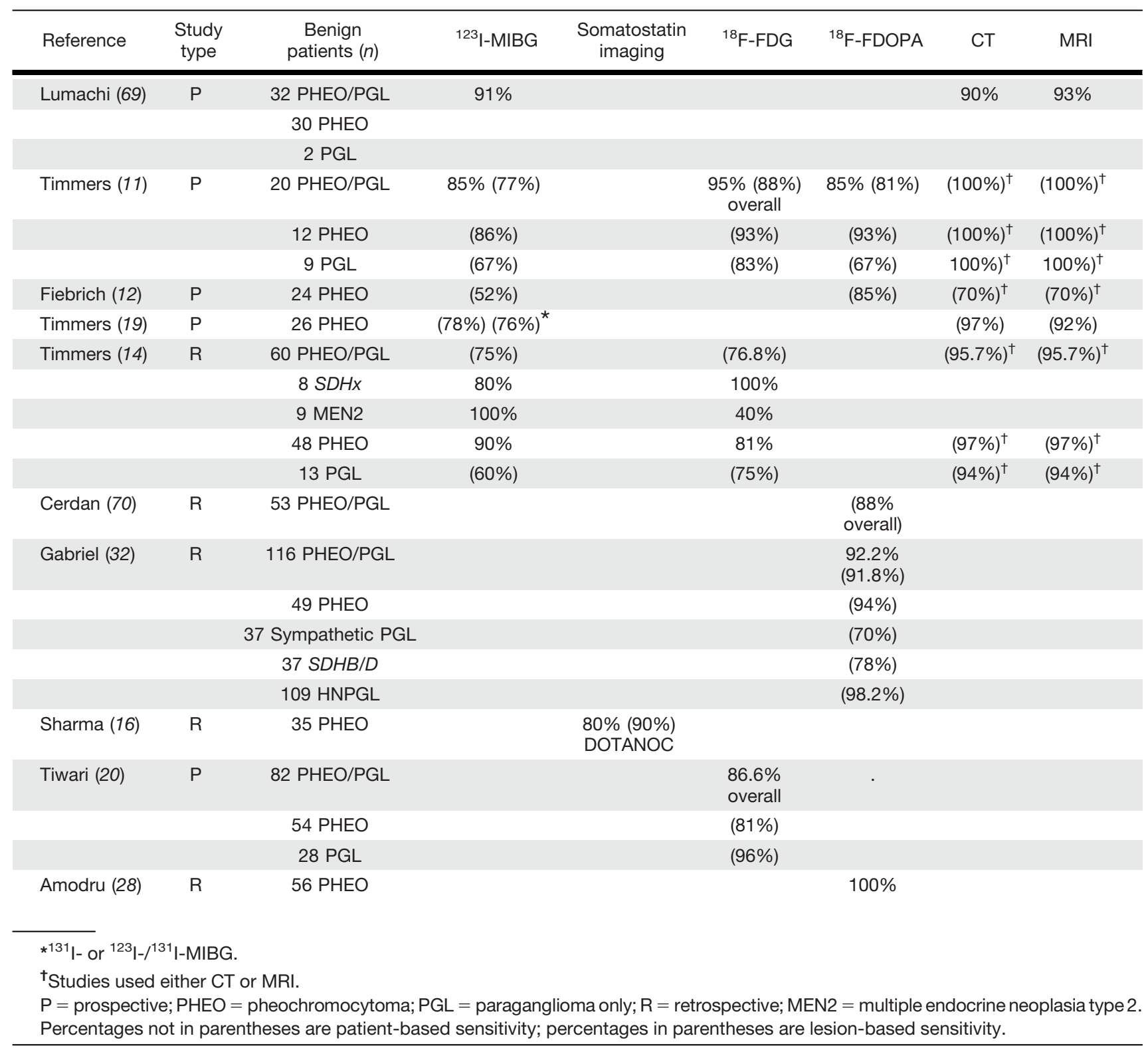

uptake of ${ }^{18}$ F-FDOPA in the normal adrenal (mean $\left.\mathrm{SUV}_{\max }, 1.9\right)$ is advantageous compared with the prominent uptake of ${ }^{123} \mathrm{I}-\mathrm{MIBG}$ (30).

\section{Clinical Results}

The utility of ${ }^{18} \mathrm{~F}$-FDOPA in pheochromocytoma/paraganglioma imaging is presented in Tables 1 and 2. A metaanalysis of pheochromocytoma and paraganglioma demonstrated pooled ${ }^{18} \mathrm{~F}-\mathrm{FDOPA}$ PET/CT sensitivities and specificities of $91 \%$ and $79 \%$, respectively, on a per-patient basis and $95 \%$ and $95 \%$, respectively, on a per-lesion basis (31). Table 1 shows ${ }^{18}$ F-FDOPA to have a high sensitivity (85\%-100\%) that outperforms MIBG in benign pheochromocytoma. The sensitivity of ${ }^{18}$ F-FDOPA for benign pheochromocytoma (94\%) is better than that for benign sympathetic paraganglioma (70\%) (32). The sensitivity for detecting metastatic pheochromocytoma can be more than $90 \%(23,33,34)$ in non-SDHx metastatic pheochromocytoma, although other reports show sensitivity of $81 \%$ in benign disease and $45 \%$ in malignant disease, for which many lesions may be missed (Fig. 2) (11).

In summary, ${ }^{18} \mathrm{~F}$-FDOPA has high sensitivity for detecting benign pheochromocytoma or paraganglioma and metastatic pheochromocytoma (sporadic or associated with non-SDHx mutations), but the sensitivity is lower for metastatic paraganglioma. Procedure guidelines recommend the use of ${ }^{18} \mathrm{~F}$-FDOPA in the workup for nonmetastatic pheochromocytoma and paraganglioma (35). Recent work with ${ }^{68}$ Ga-DOTA-SSA shows that in HNPGL, in metastatic sporadic pheochromocytoma or paraganglioma, and in metastatic $\mathrm{SDHx}$ related pheochromocytoma or paraganglioma, the sensitivity of ${ }^{68}$ Ga-DOTA-SSA imaging surpasses that of ${ }^{18} \mathrm{~F}$-FDOPA and other reagents. 
TABLE 2

Sensitivity of Detection of Metastatic Pheochromocytoma and Paraganglioma ( $n \geq 20$ Patients or Prospective Studies)

\begin{tabular}{|c|c|c|c|c|c|c|c|c|}
\hline Reference & $\begin{array}{l}\text { Study } \\
\text { type }\end{array}$ & $\begin{array}{l}\text { Metastatic } \\
\text { patients }(n)\end{array}$ & ${ }^{123}$ I-MIBG & $\begin{array}{l}\text { Somatostatin } \\
\text { imaging }\end{array}$ & ${ }^{18} \mathrm{~F}-\mathrm{FDG}$ & ${ }^{18}$ F-FDOPA & CT & MRI \\
\hline \multirow[t]{2}{*}{ Timmers (24) } & $\mathrm{R}$ & 30 PGL (SDHB) & $80 \%(65 \%)$ & $81 \%(59 \%)$ & $\begin{array}{l}100 \% \\
(97 \%)\end{array}$ & & $96 \%(96 \%)$ & $95 \%(95 \%)$ \\
\hline & & & & $\begin{array}{l}{ }^{111} \text { In- } \\
\text { pentetreotide }\end{array}$ & & & & \\
\hline \multirow[t]{3}{*}{ Zelinka (42) } & $\mathrm{R}$ & 71 PHEO/PGL & $71 \%{ }^{*}$ & & $76 \%$ & & $78 \%{ }^{* \dagger}$ & $78 \%$ *† \\
\hline & & $30 S D H B$ & $65 \%{ }^{\star}$ & & $92 \%$ & & $96 \%$ & $96 \%$ \\
\hline & & 41 non-SDHB & $76 \%{ }^{*}$ & & $62 \%$ & & $65 \%$ & $65 \%$ \\
\hline \multirow[t]{3}{*}{ Timmers (11) } & $\mathrm{P}$ & 28 PHEO/PGL & $85 \%(57 \%)$ & & $\begin{array}{l}89 \% \\
(74 \%)\end{array}$ & $\begin{array}{l}71 \% \\
(45 \%)\end{array}$ & $86 \%(45 \%)^{\dagger}$ & $86 \%(45 \%)^{\dagger}$ \\
\hline & & $15 S D H B$ & & & & $(20 \%)$ & & \\
\hline & & 13 non-SDHB & & & & (93\%) & & \\
\hline Timmers (19) & $P$ & 34 PHEO/PGL & $85 \%, 65 \%$ * & & & & $100 \%$ & $100 \%$ \\
\hline Fiebrich (12) & $\mathrm{R}$ & 21 PHEO & (56\%) & & & $(73 \%)$ & $(45 \%)^{\dagger}$ & $(45 \%)^{\dagger}$ \\
\hline $\begin{array}{l}\text { Cantalamessa } \\
\text { (39) }\end{array}$ & $\mathrm{R}$ & 38 PHEO/PGL & $79 \%$ & & $87 \%$ & & $87 \%$ & \\
\hline \multirow[t]{3}{*}{ Timmers (14) } & $\mathrm{R}$ & 95 & $(50 \%)$ & & (82.5\%) & & $(74.4 \%)^{\dagger}$ & $(74.4 \%)^{\dagger}$ \\
\hline & & $52 S D H x$ & (45\%) & & (92\%) & & $(78.5)^{\dagger}$ & $(78.5)^{\dagger}$ \\
\hline & & 23 non-SDHx & $(66 \%)$ & & $(67 \%)$ & & $(70 \%)^{\dagger}$ & $(70 \%)^{\dagger}$ \\
\hline Janssen (13) & $P$ & $\begin{array}{c}17 \text { PHEO/PGL } \\
(\mathrm{S} D H B)\end{array}$ & $\begin{array}{c}(18.7 \%) \\
n=6\end{array}$ & $\begin{array}{c}100 \%(98.6 \%) \\
68 \mathrm{Ga}- \\
\text { DOTATATE }\end{array}$ & $\begin{array}{c}100 \% \\
(85.8 \%)\end{array}$ & $\begin{array}{c}87.5 \% \\
(61.4 \%)\end{array}$ & $\begin{array}{c}100 \%{ }^{\dagger} \\
(84.8 \%)^{\dagger}\end{array}$ & $\begin{array}{c}100 \%{ }^{\dagger} \\
(84.8 \%)^{\dagger}\end{array}$ \\
\hline Tan (15) & $\mathrm{P}$ & 17 PHEO/PGL & $\begin{array}{c}46.7 \% \\
(15.7 \%)^{*}\end{array}$ & $\begin{array}{c}93 \%(91.5 \%) \\
68 \mathrm{Ga}- \\
\text { DOTATATE }\end{array}$ & $\begin{array}{c}90.9 \% \\
(51.3 \%)\end{array}$ & & & \\
\hline Janssen (34) & $P$ & $\begin{array}{l}22 \mathrm{PHEO} / \mathrm{PGL} \\
\text { (all sporadic) }\end{array}$ & & $\begin{array}{c}100 \%(97.6 \%) \\
68 \mathrm{Ga}- \\
\text { DOTATATE }\end{array}$ & $91 \%(49 \%)$ & $\begin{array}{c}92 \% \\
(74.8 \%)\end{array}$ & $\begin{array}{c}100 \% \\
(81.6 \%)^{\dagger}\end{array}$ & $100 \%) 81.6 \%)^{\dagger}$ \\
\hline
\end{tabular}

${ }^{* 131}$ I- or ${ }^{123} \mathrm{I}-\mathrm{I}^{131} \mathrm{I}$-MIBG.

†'Studies used either CT or MRI.

$\mathrm{R}=$ retrospective; $\mathrm{PGL}=$ paraganglioma only; $\mathrm{PHEO}=$ pheochromocytoma; $\mathrm{P}=$ prospective.

Percentages not in parentheses are patient-based sensitivity; percentages in parentheses are lesion-based sensitivity. In study of Zelinka (42), sensitivity of bone scan for metastasis was $82 \%$ overall, $95 \%$ for $S D H B$, and $70 \%$ for non-SDHB.

\section{${ }^{18}$ F-FDG}

${ }^{18} \mathrm{~F}$-FDG is a surrogate marker of glucose metabolism. Entry into tumor is mediated by glucose transporters, typically transporter-1, after which hexokinase- 2 phosphorylates it and it becomes a trapped marker.

\section{Patient Preparation, Administration, Pharmacokinetics, Biodistribution, and Dosimetry}

Procedure guidelines for ${ }^{18} \mathrm{~F}$-FDG apply to patients with pheochromocytoma or paraganglioma $(25,36)$. Patient preparation, administered activity, and dosimetry results are shown in Supplemental Table 1. The normal distribution includes uptake in the brain, urinary tract, liver, and spleen, as well as variable cardiac and bowel uptake (Fig. 1). Normal adrenals have less uptake than liver (mean $\left.\mathrm{SUV}_{\max }, 1.6\right)(14)$.

\section{Clinical Results}

The utility of ${ }^{18} \mathrm{~F}-\mathrm{FDG}$ in pheochromocytoma/paraganglioma imaging is presented in Tables 1 and 2. A metaanalysis found ${ }^{18} \mathrm{~F}$ FDG to have a sensitivity of $85 \%$ and a specificity of $55 \%$ for metastatic pheochromocytoma and paraganglioma (37). One study identified new lesions that impacted management beyond the use of conventional imaging modalities in $15 \%$ of cases (38).

${ }^{18}$ F-FDG uptake in pheochromocytoma and paraganglioma varies: in cluster 1 tumors, there is a mean $\mathrm{SUV}_{\max }$ of $13.0 \pm 6.5$ due to activation of hypoxia-signaling pathways, compared with $3.9 \pm 3.1$ for cluster 2 tumors and $9.0 \pm 7.2$ for mutation-negative tumors (20). The sensitivity of ${ }^{18} \mathrm{~F}$-FDG was only $40 \%$ in patients with multiple endocrine neoplasia type 2-associated pheochromocytoma (cluster 2) (14).

For benign pheochromocytoma and paraganglioma tumors, ${ }^{18} \mathrm{~F}$ FDG has variable sensitivity that is often lower than or similar to the sensitivity of MIBG (Fig. 1). In an early study, the sensitivity of ${ }^{18}$ F-FDG in tumor detection was $58 \%$, compared with $83 \%$ for MIBG (18). In separate reports including nonmetastatic pheochromocytoma and paraganglioma, ${ }^{18} \mathrm{~F}-\mathrm{FDG}$ had a sensitivity of between $76.8 \%$ and $88.0 \%(11,14)$.

${ }^{18} \mathrm{~F}$-FDG frequently outperforms MIBG in detecting metastatic disease $(33,39)$, with up to $90 \%$ of MIBG-negative lesions positive on ${ }^{18}$ F-FDG (Fig. 2) (15). In metastatic pheochromocytoma and paraganglioma, the sensitivity of ${ }^{18}$ F-FDG ranges from $51 \%$ to $100 \%$ 


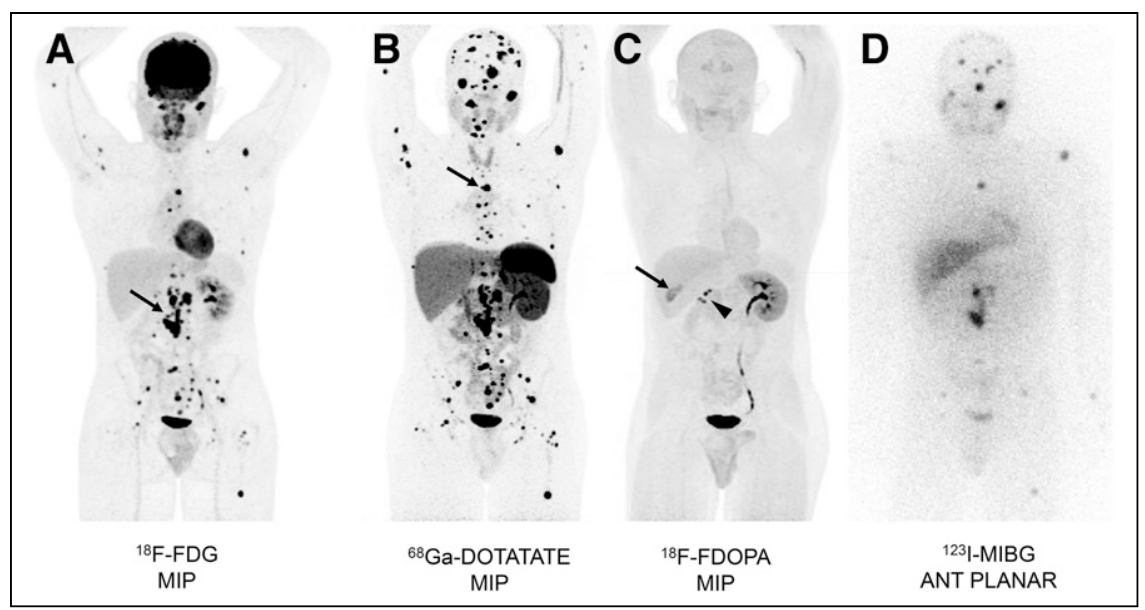

FIGURE 2. A 20-y-old man with SDHB-associated metastatic paraganglioma. (A) Maximum-intensity-projection (MIP) ${ }^{18} \mathrm{~F}$-FDG PET scan showing excellent uptake in bones and retroperitoneal metastases (SUV $\max$, 54) (arrow), with fewer lesions than on ${ }^{68} \mathrm{Ga}$-DOTATATE PET. (B) MIP ${ }^{68}$ Ga-DOTATATE PET scan showing highest contrast and number of lesions of any of the imaging modalities $\left(\mathrm{SUV}_{\max }, 94\right)$ in bone metastasis (arrow). (C) MIP ${ }^{18} \mathrm{~F}$-FDOPA PET scan showing negative findings, with some physiologic uptake in gallbladder (arrow) and urinary excretion in right atrophic kidney (arrowhead). (D) Anterior ${ }^{123}$ I-MIBG planar scan showing uptake in limited number of known metastases.

and is usually more than $80 \%(11,14,15,24,39,40)$. This wide variability is likely due to the varying characteristics of the patient population being studied and the presence or absence of specific genetic mutations, as well as differences in the gold standard considered (Table 2). In a prospective study, Timmers et al. (24) were the first to report the superiority of ${ }^{18} \mathrm{~F}-\mathrm{FDG}$ in imaging patients with $S D H B$ mutation, where per-region sensitivity for metastatic disease was $97 \%$, compared with $65 \%$ for ${ }^{123}$ I-MIBG, $50 \%$ for ${ }^{111}$ In-pentetreotide, and $83 \%$ for bone scans. Subsequent studies have confirmed the high sensitivity of ${ }^{18} \mathrm{~F}-\mathrm{FDG}$ in $S D H x$ patients, ranging from $79.4 \%$ to $100 \%(11,13,20,41-44)$. For this reason, ${ }^{18} \mathrm{~F}-\mathrm{FDG}$ was the preferred modality for metastatic disease, particularly $S D H x$, for which it had a sensitivity of $83 \%-92 \%$, compared with $62 \%$ for non-SDHx tumors $(11,42)$. Yet as discussed below, this recommendation preceded the evaluation of ${ }^{68} \mathrm{Ga}$-DOTA-SSA.

\section{${ }^{68}$ GA-DOTA-SSA}

Somatostatin, a 14-amino-acid peptide hormone, binds to somatostatin receptors (SSTRs 1, 2, 3, 4, and 5). In vitro, pheochromocytoma and paraganglioma tumors express predominantly SSTR 2 and SSTR $3(45,46)$.

Although ${ }^{111}$ In-pentetreotide was the first SSA approved for imaging NETs, it has been supplanted by DOTA-SSA, which has a stronger chelate and is labeled with ${ }^{68} \mathrm{Ga}$, a positron emitter with a 68-min half-life. ${ }^{68} \mathrm{Ga}$-DOTA-SSAs include DOTATOC (SSTRs 2 and 5), DOTANOC (SSTRs 2, 3, and 5), and DOTATATE (SSTR 2) (47). ${ }^{68} \mathrm{Ga}$-DOTATATE (Netspot; Advanced Accelerator Applications) is approved by the Food and Drug Administration and by the European Medicines Agency. This review will focus on ${ }^{68} \mathrm{Ga}-$ DOTA-SSA, with emphasis on ${ }^{68} \mathrm{Ga}$-DOTATATE since it is the most widely used in pheochromocytoma/paraganglioma imaging, recognizing that ${ }^{68} \mathrm{Ga}$-DOTATOC is also effective and that ${ }^{64} \mathrm{Cu}-$ DOTATATE (Detectnet; Curium) is probably a suitable alternative, although there are no published reports on pheochromocytoma or paraganglioma (Supplemental Table 1). Existing guidelines that recommend ${ }^{18} \mathrm{~F}$ FDG imaging may be outdated by current practice, given clinical understanding of the superiority of ${ }^{68}$ Ga-DOTA-SSA.

\section{Patient Preparation, Administration, Pharmacokinetics, Biodistribution, and Dosimetry}

Procedure guidelines for ${ }^{68} \mathrm{Ga}$-DOTASSA have been published $(25,26)$. The recommendations to discontinue SSAs are likely unnecessary (Supplemental Table 1). Administered activity, special considerations, and dosimetry are presented in Supplemental Table 1. The biodistribution of ${ }^{68} \mathrm{Ga}$-DOTATATE/TOC has been reported (48). Clearance from the blood is rapid. Renal clearance predominates. Prominent uptake occurs in the spleen, kidney, adrenal glands, pituitary gland, and liver (Fig. 1), with minor differences between analogs (48). Most tumor uptake occurs by $30 \mathrm{~min}$ after injection. Low uptake is seen in the salivary glands and thyroid. ${ }^{68} \mathrm{Ga}$-DOTATATE $\mathrm{SUV}_{\text {max }}$ is higher in normal adrenals (range, 16.4-20.3) than in benign adenomas (range, 6.3-11.8) (49). In contrast, paraganglioma have a mean $\mathrm{SUV}_{\max }$ of 94.2 (range, 33.15-155.2).

\section{Clinical Results}

The utility of ${ }^{68} \mathrm{Ga}$-DOTA-SSA in pheochromocytoma/paraganglioma imaging is presented in Tables 1 and 2. ${ }^{68}$ Ga-DOTA-SSA studies have shown excellent lesion-based sensitivity in detecting pheochromocytoma and paraganglioma, often more than $92 \%$ $(16,40,50)$. Recent publications suggest that ${ }^{68} \mathrm{Ga}$-DOTA-SSA provides a high detection rate across a wide range of mutations $(34,44,51,52)$. A metaanalysis comparing the sensitivity of ${ }^{18} \mathrm{~F}$ FDG and ${ }^{68} \mathrm{Ga}-D O T A-S S A$ found that the sensitivity of ${ }^{68} \mathrm{Ga}-$ DOTA-SSA (95\%) was superior to that of ${ }^{18}$ F-FDG (85\%). Even when germline mutations were considered, the per-lesion sensitivity of ${ }^{68} \mathrm{Ga}$-DOTA-SSA was $97 \%$, compared with $79 \%$ for ${ }^{18} \mathrm{~F}$-FDG (37). An additional metaanalysis demonstrated that the sensitivity of ${ }^{68} \mathrm{Ga}$-DOTA-SSA $(93 \%)$ is superior to that of ${ }^{18} \mathrm{~F}$-FDOPA $(80 \%),{ }^{18}$ F-FDG (74\%), and ${ }^{123} \mathrm{I} /{ }^{131} \mathrm{I}-\mathrm{MIBG}$ (38\%) (53).

In a prospective trial of 22 patients with sporadic metastatic pheochromocytoma or paraganglioma, ${ }^{68} \mathrm{Ga}$-DOTATATE detected $98 \%$ of metastases, outperforming ${ }^{18} \mathrm{~F}-\mathrm{FDG}$ (49.2\%), ${ }^{18} \mathrm{~F}$-FDOPA (74.8\%), and CT/MRI (81.6\%) (34). In patients with SDHx mutations, the per-lesion sensitivity of ${ }^{68} \mathrm{Ga}$-DOTATATE is higher than that of ${ }^{18}$ F-FDG (Fig. 2) or CT/MRI $(13,43,44)$. Overall, ${ }^{68} \mathrm{Ga}$-DOTATATE should be considered the tracer of choice for evaluating metastatic pheochromocytoma, metastatic paraganglioma, SDHx mutations, and HNPGL. An exception is pheochromocytoma or paraganglioma associated with polycythemia, MAX mutations, or apparently sporadic pheochromocytoma, for which ${ }^{18}$ F-FDOPA may be preferable. Limited studies have evaluated the use of SSAs in benign pheochromocytoma. In a study of 32 patients, ${ }^{111}$ In-pentetreotide had a sensitivity of $25 \%$ (54), whereas that of ${ }^{68} \mathrm{Ga}$-DOTA-SSA was expected to be higher and ${ }^{18} \mathrm{~F}$ DOPA was still the preferred agent. 


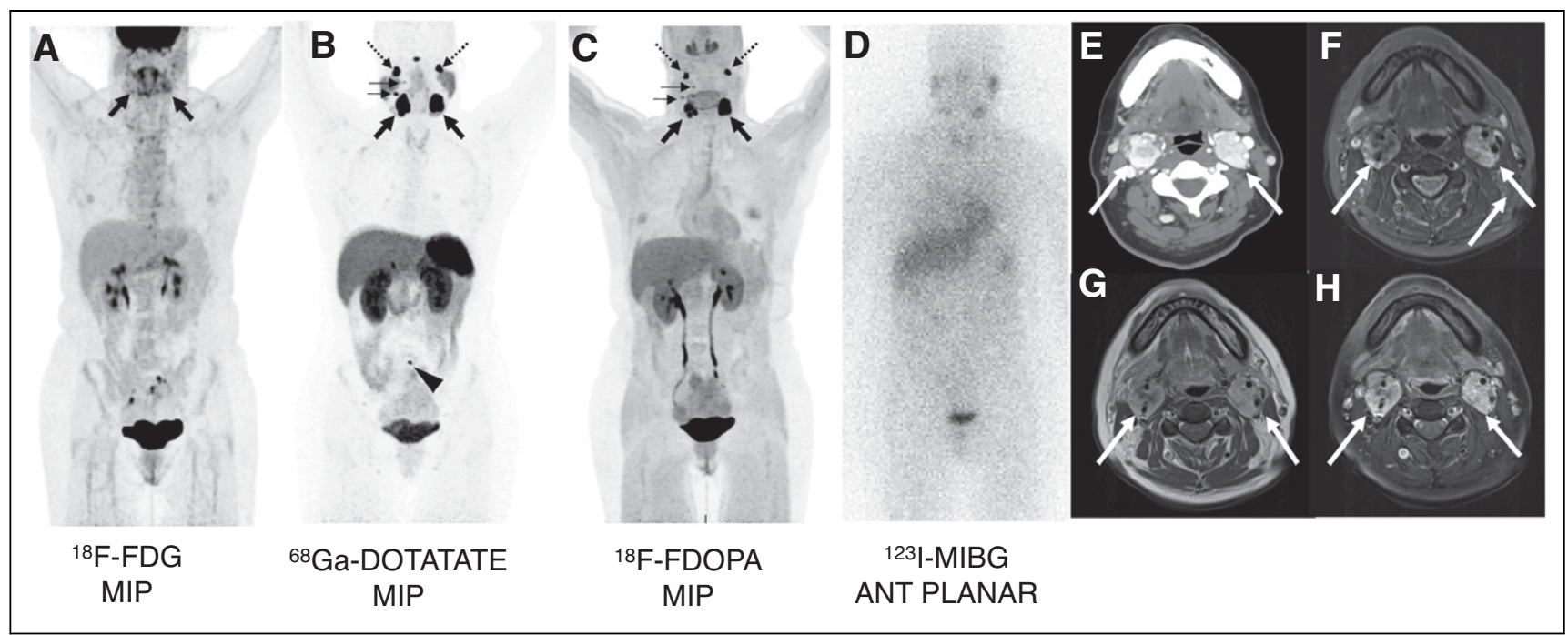

FIGURE 3. A 46-y-old woman with $S D H D$-associated HNPGL and metastases in lymph nodes and bones. (A) Maximum-intensity-projection (MIP) ${ }^{18} \mathrm{~F}-$ FDG PET scan showing carotid-body uptake (arrows) that is minor on right and slightly more prominent on left (SUV max $_{4} 4.4$ and 10.3 , respectively) but not definitively identifying any other lesions. (B and C) MIP ${ }^{68}$ Ga-DOTATATE (B) and ${ }^{18}$ F-FDOPA (C) PET scans. Right and left carotid body tumors (horizontal solid arrows) are best identified in these (SUV $\max , 134.6$ and 199.1 , respectively, for ${ }^{68} \mathrm{Ga}$-DOTATATE and 28.1 and 46.4 , respectively, for $\left.{ }^{18} \mathrm{~F}-\mathrm{FDOPA}\right)$. Also seen are bilateral uptake in glomus jugulare paraganglioma (dashed arrows), as well as lymph node metastases (horizontal solid arrows). Highest contrast is noted in ${ }^{68} \mathrm{Ga}$-DOTATATE scan, which also identified L5 bone metastasis (arrowhead), not identified in any other functional modality. (D) Anterior ${ }^{123}$ I-MIBG planar scan with negative findings and showing normal salivary glands. (E) Axial contrast-enhanced CT scan showing enhancing right carotid body $(2.1 \mathrm{~cm})$ and left carotid body paraganglioma $(2.7 \mathrm{~cm})$ (arrows). $(\mathrm{F}-\mathrm{H})$ Axial short- $\tau$ inversion recovery MRI scan $(\mathrm{F})$, contrast-enhanced T1-weighted MRI scan (G), and fat-suppressed contrast-enhanced T1-weighted MRI scan $(\mathrm{H})$ demonstrating bilateral heterogeneous uptake (arrows). Lymph node metastases seen on ${ }^{68} \mathrm{Ga}$-DOTATATE and ${ }^{18} \mathrm{~F}$-FDOPA were retrospectively identified on CT as subcentimeter lesions (not shown); however, on MRI they were difficult to discern from normal lymph nodes in region. Glomus jugulare paragangliomas seen bilaterally on ${ }^{68} \mathrm{Ga}$-DOTATATE and ${ }^{18} \mathrm{~F}$-FDOPA were not seen on CT or MRI.

\section{CT AND MRI}

CT and MRI (Supplemental Fig. 1) play an important role in diagnosis, staging, and therapy response assessment in patients with pheochromocytoma or paraganglioma. These modalities are used presurgically to determine the site of disease and the relationship to other structures. Current guidelines suggest $\mathrm{CT}$ rather than MRI for initial localization in biochemically positive patients (35). MRI is preferable for pediatric patients and for screening because of its lack of ionizing radiation.

A small percentage of pheochromocytoma cases present as adrenal incidentalomas, whereas approximately $75 \%$ of incidentalomas are adenomas (55). CT and MRI are used to differentiate between adenoma and other adrenal lesions, including pheochromocytoma (Supplemental Fig. 1). On unenhanced CT, 99.6\% of pheochromocytomas have more than 10 Hounsfield units (HU) (56). Whereas most adenomas have $10 \mathrm{HU}$ or less, the less common lipid-poor adenomas also have more than $10 \mathrm{HU}$. Contrast-enhanced CT is used to determine absolute and relative percentage contrast washout between the portal-venous and delayed phases; values of at least $60 \%$ and at least $40 \%$, for absolute and relative washout, respectively, are typical of lipid-poor adenomas but unfortunately overlap those of pheochromocytoma (57). Venous-phase enhancement of at least $85 \mathrm{HU}$ was seen in $88 \%$ of pheochromocytomas but in only $16 \%$ of adenomas. Because pheochromocytomas can be large, they may present with central necrosis that does not enhance with contrast (ring sign) on CT or MRI. Regardless of washout, growing adrenal lesions and those larger than 4-5 cm usually require further workup, such as resection or biopsy.

MRI also recognizes adenomas by their lipid content using chemical shift sequences, and the discovery of a high lipid content is generally diagnostic of adenoma. Lipid-poor adenoma findings may overlap with the findings of pheochromocytoma on MRI and MRI washout (58). A high signal intensity on T2-weighted images, particularly those with fat suppression, has been described as characteristic of pheochromocytoma and paraganglioma (Supplemental Fig. 1), and although highly sensitive, this finding lacks specificity.

Patients with metastatic disease undergo whole-body CT or MRI for staging and presurgical evaluation of pheochromocytoma and paraganglioma and for assessment of disease progression and treatment response. Nonetheless, in cases of metastatic disease, functional imaging often has higher sensitivity for tumor detection, given the high incidence of bone metastases and small soft-tissue lesions that may be difficult to visualize with CT or MRI.

\section{HNPGL}

HNPGL most commonly arises in the carotid body and jugulotympanic regions, but concurrent tumors below the neck may be present. Germline mutations, most commonly $S D H D$ and $S D H B$, are responsible for $25 \%-50 \%$ of HNPGL (59).

First-line imaging of HNPGL for staging, determining locoregional extent, and planning treatment generally involves anatomic imaging such as MRI, MR angiography, CT, and CT angiography (60). On CT imaging (Fig. 3), HNPGLs are hypervascular, with intense early arterial-phase enhancement that is also present on contrast-enhanced MRI, often with a salt-and-pepper appearance. MRI and MR angiography are usually performed to determine the extent of involvement, support disease management, evaluate risk, and estimate prognosis. MRI can involve a series of time-consuming sequences. A prospective trial of HNPGL associated with $S D H x$ limited the sequences to a short contrast-enhanced MRI protocol consisting of a 3-dimensional time- 
TABLE 3

Sensitivity of Detection for HNPGL

\begin{tabular}{|c|c|c|c|c|c|c|c|c|}
\hline Reference & $\begin{array}{l}\text { Study } \\
\text { type }\end{array}$ & $\begin{array}{l}\text { Head and neck } \\
\text { patients }(n)\end{array}$ & ${ }^{123} \mathrm{I}-\mathrm{MIBG}$ & $\begin{array}{l}\text { Somatostatin } \\
\text { imaging }\end{array}$ & ${ }^{18} \mathrm{~F}-\mathrm{FDG}$ & ${ }^{18}$ F-FDOPA & CT & MRI \\
\hline Hoegerle (63) & $\mathrm{P}$ & $\begin{array}{c}10 \text { (15 lesions) } \\
\text { (SDHD) }\end{array}$ & & & & $100 \%(100 \%)$ & & $90 \%(73 \%)$ \\
\hline King (62) & $\mathrm{P}$ & $\begin{array}{c}10 \text { (26 lesions) } \\
(S D H x)\end{array}$ & $40 \%(30.7 \%)$ & $\begin{array}{c}78 \%(64 \%) \\
{ }^{111} \text { In-pentetreotide }\end{array}$ & $80 \%(77 \%)$ & $100 \%(100 \%)$ & $100 \%(80.7 \%)^{\star}$ & $100 \%{ }^{\star}(80.7 \%)^{\star}$ \\
\hline Gabriel (32) & $\mathrm{R}$ & $\begin{array}{l}100(\mathrm{HNPGL}+ \\
3 \text { thoracic PGL) }\end{array}$ & & & & $(98.2 \%)$ & & \\
\hline \multirow[t]{3}{*}{ Blanchet (64) } & $\mathrm{R}$ & 60 (106 lesions) & & & $86.6 \%(90.5 \%)$ & & & \\
\hline & & 32 SDHx & & & $84.4 \%$ (90.9\% & & & \\
\hline & & 28 non-SDHx & & & $89.3 \%(90.4 \%)$ & & & \\
\hline Janssen (52) & $P$ & $\begin{array}{c}20 \text { (38 lesions) } \\
(16 \mathrm{SDHx})\end{array}$ & & $\begin{array}{l}100 \%(100 \%) \\
{ }^{68} \mathrm{Ga} \text {-DOTATATE }\end{array}$ & $80 \%(71 \%)$ & $95 \%(97.4 \%)$ & $(60.5)^{\star}$ & $(60.5 \%)^{\star}$ \\
\hline Archier (50) & $\mathrm{P}$ & $\begin{array}{c}30 \text { (30 lesions) } \\
(18 S D H D)\end{array}$ & & $\begin{array}{c}(100 \%) \\
{ }^{68} \text { Ga-DOTATATE }\end{array}$ & & $(86.7 \%)$ & & $(80 \%)^{\star}$ \\
\hline
\end{tabular}

*Studies used either CT or MRI.

$\mathrm{P}=$ prospective; $\mathrm{PGL}=$ paraganglioma; $\mathrm{R}=$ retrospective.

Percentages not in parentheses are patient-based sensitivity; percentages in parentheses are lesion-based sensitivity.

of-flight MR angiographic sequence and an axial-plane fast spin-echo T1-weighted sequence with fat saturation. These sequences had sensitivity and specificity of $88.7 \%$ and $93.7 \%$, respectively, for identifying HNPGL (61).

${ }^{68} \mathrm{Ga}$-DOTA-SSA, ${ }^{18} \mathrm{~F}$-FDOPA, and to a lesser extent ${ }^{18} \mathrm{~F}$-FDG imaging have high sensitivity for HNPGL (Fig. 3), whereas the sensitivity of ${ }^{123} \mathrm{I} /{ }^{131} \mathrm{I}-\mathrm{MIBG}$ is poor $(10 \%-42 \%)$ (Fig. 3 ; Table 3$)$. The sensitivity of ${ }^{68} \mathrm{Ga}$-DOTATATE was $100 \%$ for HNPGL, with identification of additional lesions not visualized with other modalities (52). The sensitivity of ${ }^{18}$ F-FDOPA was also high (97\%), although ${ }^{18} \mathrm{~F}$-FDOPA detected only $60 \%,{ }^{18} \mathrm{~F}$-FDG only $70 \%$, and CT or MRI only $77 \%$ of lesions outside the head and neck, whereas ${ }^{68} \mathrm{Ga}-$ DOTATATE detected 100\%. (52)

${ }^{18}$ F-FDOPA has a high sensitivity $(86.7 \%-100 \%)$ for HNPGL $(23,31,32,50,62,63)$ - a sensitivity that surpasses that of MRI (Table 3) $(50,62,63)$. Furthermore, interpretations of ${ }^{18}$ F-FDOPA were more reproducible than those of MR angiography and were often more informative than the MRI reading by directing attention to lesions that otherwise might have been missed $(50,63) .{ }^{18} \mathrm{~F}$-FDOPA has been considered a first-line imaging modality for HNPGL, although recent results for ${ }^{68}$ Ga-DOTA-SSA are superior $(25,35)$.

The sensitivity of ${ }^{18} \mathrm{~F}$-FDG in HNPGL ranges from $71 \%$ to $90.5 \%$ $(52,62,64)$ but was not as high as that of ${ }^{68} \mathrm{Ga}$-DOTA-SSA or ${ }^{18} \mathrm{~F}$ FDOPA. One group reported a $71 \%$ per-lesion sensitivity for ${ }^{18} \mathrm{~F}$ FDG in a separate HNPGL patient group in which ${ }^{18} \mathrm{~F}$-FDOPA had a sensitivity of $97 \%$ (52).

In summary, in patients with HNPGL or at high risk of developing HNPGL, functional imaging has high sensitivity and should be used in conjunction with MRI, with the latter required for surgical and treatment planning. In almost every situation, ${ }^{68}$ Ga-DOTA-SSA is considered the agent of choice, ${ }^{18}$ F-FDOPA the second choice, and ${ }^{18}$ F-FDG the third choice (Fig. 4).

\section{PEDIATRIC PHEOCHROMOCYTOMA AND PARAGANGLIOMA}

Ten to twenty percent of pheochromocytoma and paraganglioma cases occur in children (65), and most are hereditary (66). Pheochromocytoma is present bilaterally in $19 \%$ of cases, and $4 \%-65 \%$ present with or develop metastases $(67,68)$. Babic et al. (68) reported the sensitivity in pediatric pheochromocytoma of CT (100\%), MRI (93\%), ${ }^{18}$ F-FDG (86\%), MIBG (91\%), ${ }^{18}$ F-FDOPA (100\%), and ${ }^{68} \mathrm{Ga}$-DOTATATE $(100 \%)$. Jha et al. (44) found that in 9 cases of pediatric $S D H x$ pheochromocytoma or paraganglioma, the perpatient sensitivity was $100 \%$ for ${ }^{18}$ F-FDG and ${ }^{68}$ Ga-DOTATATE but the per-lesion sensitivity was lower $(79.4 \%$ vs. $93.5 \%$, respectively). Furthermore, ${ }^{68}$ Ga-DOTATATE was more sensitive than CT or MRI (73.8\%). However, for abdominal lesions, the sensitivity of ${ }^{68} \mathrm{Ga}$-DOTATATE was $67 \%$, whereas that of both ${ }^{18} \mathrm{~F}$-FDG and CT or MRI was $80 \%$. Thus, ${ }^{68} \mathrm{Ga}$-DOTATATE PET/CT is recommended as the functional imaging modality in pediatric SDHx with the exception of abdominal lesions, for which contrastenhanced ${ }^{68} \mathrm{Ga}$-DOTATATE PET/CT or PET/MRI is suggested, although this exception warrants corroboration in larger numbers of patients.

\section{IMAGING OF SPECIFIC MUTATIONS}

Imaging phenotypes differ among germline mutations, although for some, data are very limited. Supplemental Table 2 provides some of the studies that described sensitivity results, as well as some of the relevant features regarding the presentation of the pheochromocytoma and paraganglioma cases associated with these mutations (RET, VHL, NF1, SDHx, EPAS1, and MAX). The best imaging data are for $S D H x$-related pheochromocytoma and paraganglioma, for which ${ }^{68} \mathrm{Ga}$-DOTATATE is the radiopharmaceutical of choice. ${ }^{18} \mathrm{~F}-\mathrm{FDG}$ also has high sensitivity in these patients, although for HNPGL, ${ }^{18} \mathrm{~F}$-FDOPA is the second choice (Supplemental Table 2). In patients with $V H L, R E T$, and $N F 1$ mutations, ${ }^{18} \mathrm{~F}$-FDOPA is the most sensitive agent for tumor detection, but with limited comparisons with ${ }^{68} \mathrm{Ga}$-DOTATATE and ${ }^{18} \mathrm{~F}$-FDG available. A study by Sharma et al. suggests high sensitivity for ${ }^{68} \mathrm{Ga}$-DOTANOC in patients with RET mutation (Supplemental Table 2) (16). Pheochromocytomas and paragangliomas associated with HIF2A (also known as EPAS1) and EGLN1 present with polycythemia, and those pheochromocytomas associated with $M A X$ are better imaged with ${ }^{18} \mathrm{~F}$ - 


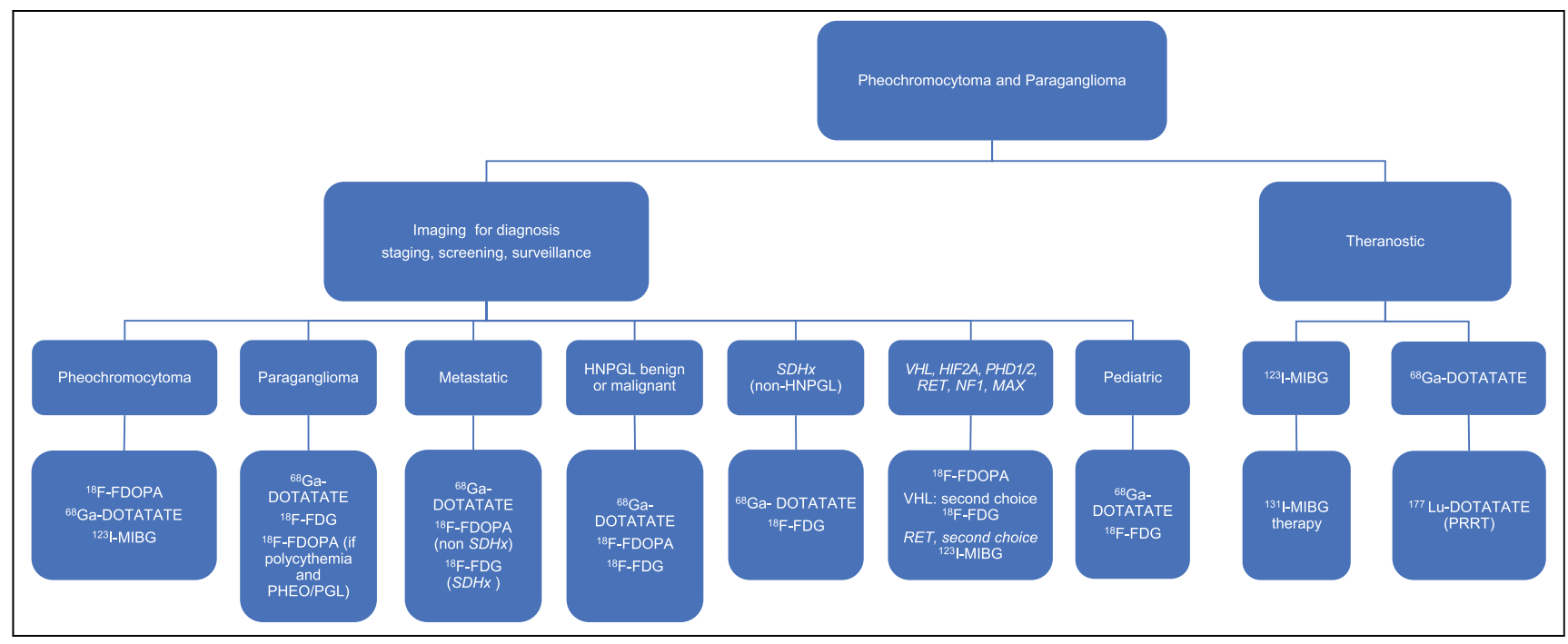

FIGURE 4. Suggested imaging algorithm for various scenarios. If mutation status is unknown and only pheochromocytoma is present, ${ }^{18} \mathrm{~F}-\mathrm{FDOPA}$ is first choice, followed by ${ }^{68} \mathrm{Ga}$-DOTATATE. For benign HNPGLs, ${ }^{68} \mathrm{Ga}$-DOTATATE is first choice, followed by ${ }^{18} \mathrm{~F}$-FDOPA and then ${ }^{18} \mathrm{~F}$-FDG. For metastatic disease outside head and neck, ${ }^{68} \mathrm{Ga}$-DOTATATE is first choice, followed by ${ }^{18} \mathrm{~F}$-FDG if $S D H x$ and ${ }^{18} \mathrm{~F}$-FDOPA if non-SDHx. If mutation status is unknown in pediatric patient, ${ }^{68} \mathrm{Ga}$-DOTATATE is first choice, although this recommendation is based on data from small number of patients. In pediatric SDHx-related pheochromocytoma or paraganglioma, ${ }^{68} \mathrm{Ga}$-DOTATATE was inferior to ${ }^{18} \mathrm{~F}$-FDG for abdominal lesions; thus, the recommendation is that ${ }^{68} \mathrm{Ga}$-DOTATATE be supplemented with contrast-enhanced CT/MRI or that ${ }^{68} \mathrm{Ga}-\mathrm{DOTATATE} P E T / \mathrm{MRI}$ be performed with intravenous contrast medium. $\mathrm{PHEO} / \mathrm{PGL}=$ pheochromocytoma or paraganglioma; PRRT = peptide receptor radionuclide therapy.

FDOPA, whereas imaging with ${ }^{18}$ F-FDG or ${ }^{68}$ Ga-DOTA-SSA had low sensitivity (Supplemental Table 2).

\section{CONCLUSION}

Pheochromocytoma and paraganglioma are complex molecularly driven diseases, with an increasing number of driver mutations identified. Because pheochromocytoma and paraganglioma are rare, studies are limited, typically small, and frequently retrospective. The identified pheochromocytoma and paraganglioma genotypes demonstrate imaging phenotypes that, although not perfectly predictive, offer guidance on the best functional imaging approaches. Frequently, PET/CT with ${ }^{68} \mathrm{Ga}$-DOTA-SSA has the highest diagnostic accuracy across imaging modalities. ${ }^{123} \mathrm{I}-\mathrm{MIBG},{ }^{18} \mathrm{~F}-\mathrm{FDOPA}$, and ${ }^{18} \mathrm{~F}-\mathrm{FDG}$ can also be useful, especially in certain clinical presentations, in specific mutations, or for evaluating therapeutic options. Other tracers that target norepinephrine transporters are not routinely available and are thus beyond the scope of this review. This review has considered numerous studies using radiopharmaceuticals approved by the Food and Drug Administration or the European Medicines Agency. On the basis of this literature, we propose the imaging algorithm presented in Figure 4.

\section{REFERENCES}

1. Lloyd RV, Osamura YR. Kloppel G, Rosa J. Who Classification of Tumours of Endocrine Organs. 4th ed. Vol 10. World Health Organization; 2017.

2. Turkova H, Prodanov T, Maly M, et al. Characteristics and outcomes of metastatic $S D H B$ and sporadic pheochromocytoma/paraganglioma: an National Institutes of Health study. Endocr Pract. 2016;22:302-314.

3. Ezzat Abdel-Aziz T, Prete F, Conway G, et al. Phaeochromocytomas and paragangliomas: a difference in disease behaviour and clinical outcomes. J Surg Oncol. 2015;112:486-491.

4. Eisenhofer G, Lenders JW, Timmers H, et al. Measurements of plasma methoxytyramine, normetanephrine, and metanephrine as discriminators of different hereditary forms of pheochromocytoma. Clin Chem. 2011;57:411-420.
5. Crona J, Taieb D, Pacak K. New perspectives on pheochromocytoma and paraganglioma: toward a molecular classification. Endocr Rev. 2017;38:489-515.

6. Wieland DM, Wu JI, Brown LE, Mangner TJ, Swanson DP, Beierwaltes WH. Radiolabeled adrenergic neuron-blocking agents: adrenomedullary imaging with [I131]iodobenzylguanidine. J Nucl Med. 1980;21:349-353.

7. Bombardieri E, Giammarile F, Aktolun C, et al. ${ }^{131} \mathrm{I} /{ }^{123} \mathrm{I}$-metaiodobenzylguanidine (MIBG) scintigraphy: procedure guidelines for tumour imaging. Eur J Nucl Med Mol Imaging. 2010;37:2436-2446.

8. Furuta N, Kiyota H, Yoshigoe F, Hasegawa N, Ohishi Y. Diagnosis of pheochromocytoma using $\left[{ }^{123} \mathrm{I}\right]$-compared with $\left[{ }^{131} \mathrm{I}\right]$-metaiodobenzylguanidine scintigraphy. Int J Urol. 1999;6:119-124.

9. Coleman RE, Stubbs JB, Barrett JA, de la Guardia M, Lafrance N, Babich JW. Radiation dosimetry, pharmacokinetics, and safety of Ultratrace ${ }^{\mathrm{TM}}$ iobenguane I-131 in patients with malignant pheochromocytoma/paraganglioma or metastatic carcinoid. Cancer Biother Radiopharm. 2009;24:469-475.

10. Van Der Horst-Schrivers AN, Jager PL, Boezen HM, Schouten JP, Kema IP, Links TP. Iodine-123 metaiodobenzylguanidine scintigraphy in localising phaeochromocytomas: experience and meta-analysis. Anticancer Res. 2006;26:1599-1604.

11. Timmers HJ, Chen CC, Carrasquillo JA, et al. Comparison of ${ }^{18} \mathrm{~F}$-fluoro-L-DOPA, ${ }^{18} \mathrm{~F}$-fluoro-deoxyglucose, and ${ }^{18} \mathrm{~F}$-fluorodopamine PET and ${ }^{123} \mathrm{I}-\mathrm{MIBG}$ scintigraphy in the localization of pheochromocytoma and paraganglioma. J Clin Endocrinol Metab. 2009;94:4757-4767.

12. Fiebrich HB, Brouwers AH, Kerstens MN, et al. 6-[F-18]fluoro-L-dihydroxyphenylalanine positron emission tomography is superior to conventional imaging with ${ }^{123} \mathrm{I}$ metaiodobenzylguanidine scintigraphy, computer tomography, and magnetic resonance imaging in localizing tumors causing catecholamine excess. J Clin Endocrinol Metab. 2009;94:3922-3930.

13. Janssen I, Blanchet EM, Adams K, et al. Superiority of $\left[{ }^{68} \mathrm{Ga}\right]$-DOTATATE PET/CT to other functional imaging modalities in the localization of SDHB-associated metastatic pheochromocytoma and paraganglioma. Clin Cancer Res. 2015;21:3888-3895.

14. Timmers HJ, Chen CC, Carrasquillo JA, et al. Staging and functional characterization of pheochromocytoma and paraganglioma by ${ }^{18} \mathrm{~F}$-fluorodeoxyglucose $\left({ }^{18} \mathrm{~F}-\mathrm{FDG}\right)$ positron emission tomography. J Natl Cancer Inst. 2012;104:700-708.

15. Tan TH, Hussein Z, Saad FF, Shuaib IL. Diagnostic performance of ${ }^{68}$ Ga-DOTATATE PET/CT, ${ }^{18}$ F-FDG PET/CT and ${ }^{131}$ I-MIBG scintigraphy in mapping metastatic pheochromocytoma and paraganglioma. Nucl Med Mol Imaging. 2015;49: 143-151.

16. Sharma P, Dhull VS, Arora S, et al. Diagnostic accuracy of ${ }^{68}$ Ga-DOTANOC PET/ CT imaging in pheochromocytoma. Eur J Nucl Med Mol Imaging. 2014;41:494-504.

17. Shapiro B, Copp JE, Sisson JC, Eyre PL, Wallis J, Beierwaltes WH. I-131 metaiodobenzylguanidine for the locating of suspected pheochromocytoma: experience in 400 cases. J Nucl Med. 1985;26:576-585. 
18. Shulkin BL, Thompson NW, Shapiro B, Francis IR, Sisson JC. Pheochromocytomas: imaging with 2-[fluorine-18]fluoro-2-deoxy-D-glucose PET. Radiology. 1999;212: 35-41.

19. Timmers HJ, Eisenhofer G, Carrasquillo JA, et al. Use of 6-[ $\left.{ }^{18} \mathrm{~F}\right]$-fluorodopamine positron emission tomography (PET) as first-line investigation for the diagnosis and localization of non-metastatic and metastatic phaeochromocytoma (pheo). Clin Endocrinol (Oxf). 2009;71:11-17.

20. Tiwari A, Shah N, Sarathi V, et al. Genetic status determines ${ }^{18}$ F-FDG uptake in pheochromocytoma/paraganglioma. J Med Imaging Radiat Oncol. 2017;61:745-752.

21. Wiseman GA, Pacak K, O'Dorisio MS, et al. Usefulness of ${ }^{123}$ I-MIBG scintigraphy in the evaluation of patients with known or suspected primary or metastatic pheochromocytoma or paraganglioma: results from a prospective multicenter trial. J Nucl Med. 2009;50:1448-1454.

22. Bhatia KS, Ismail MM, Sahdev A, et al. ${ }^{123}$ I-metaiodobenzylguanidine (MIBG) scintigraphy for the detection of adrenal and extra-adrenal phaeochromocytomas: CT and MRI correlation. Clin Endocrinol (Oxf). 2008;69:181-188.

23. Fottner C, Helisch A, Anlauf M, et al. $6-{ }^{18}$ F-fluoro-L-dihydroxyphenylalanine positron emission tomography is superior to ${ }^{123} \mathrm{I}$-metaiodobenzyl-guanidine scintigraphy in the detection of extraadrenal and hereditary pheochromocytomas and paragangliomas: correlation with vesicular monoamine transporter expression. JClin Endocrinol Metab. 2010;95:2800-2810.

24. Timmers HJ, Kozupa A, Chen CC, et al. Superiority of fluorodeoxyglucose positron emission tomography to other functional imaging techniques in the evaluation of metastatic SDHB-associated pheochromocytoma and paraganglioma. J Clin Oncol. 2007;25:2262-2269.

25. Taïeb D, Hicks RJ, Hindie E, et al. European Association of Nuclear Medicine practice guideline/Society of Nuclear Medicine and Molecular Imaging procedure standard 2019 for radionuclide imaging of phaeochromocytoma and paraganglioma. Eur J Nucl Med Mol Imaging. 2019;46:2112-2137.

26. Bozkurt MF, Virgolini I, Balogova S, et al. Guideline for PET/CT imaging of neuroendocrine neoplasms with ${ }^{68} \mathrm{Ga}$-DOTA-conjugated somatostatin receptor targeting peptides and ${ }^{18}$ F-DOPA. Eur J Nucl Med Mol Imaging. 2017;44:1588-1601.

27. Timmers HJ, Hadi M, Carrasquillo JA, et al. The effects of carbidopa on uptake of $6-{ }^{18}$ F-fluoro-L-dopa in PET of pheochromocytoma and extraadrenal abdominal paraganglioma. J Nucl Med. 2007;48:1599-1606.

28. Amodru V, Guerin C, Delcourt S, et al. Quantitative ${ }^{18}$ F-DOPA PET/CT in pheochromocytoma: the relationship between tumor secretion and its biochemical phenotype. Eur J Nucl Med Mol Imaging. 2018;45:278-282.

29. Chondrogiannis S, Marzola MC, Al-Nahhas A, et al. Normal biodistribution pattern and physiologic variants of ${ }^{18}$ F-DOPA PET imaging. Nucl Med Commun. 2013;34: 1141-1149.

30. Taïeb D, Jha A, Guerin C, et al. ${ }^{18}$ F-FDOPA PET/CT imaging of MAX-related pheochromocytoma. J Clin Endocrinol Metab. 2018;103:1574-1582.

31. Treglia G, Cocciolillo F, de Waure C, et al. Diagnostic performance of ${ }^{18} \mathrm{~F}$-dihydroxyphenylalanine positron emission tomography in patients with paraganglioma: a meta-analysis. Eur J Nucl Med Mol Imaging. 2012;39:1144-1153.

32. Gabriel S, Blanchet EM, Sebag F, et al. Functional characterization of nonmetastatic paraganglioma and pheochromocytoma by ${ }^{18} \mathrm{~F}-\mathrm{FDOPA}$ PET: focus on missed lesions. Clin Endocrinol (Oxf). 2013;79:170-177.

33. Taïeb D, Tessonnier L, Sebag F, et al. The role of ${ }^{18}$ F-FDOPA and ${ }^{18}$ F-FDG-PET in the management of malignant and multifocal phaeochromocytomas. Clin Endocrinol (Oxf). 2008;69:580-586.

34. Janssen I, Chen CC, Millo CM, et al. PET/CT comparing ${ }^{68} \mathrm{Ga}$-DOTATATE and other radiopharmaceuticals and in comparison with CT/MRI for the localization of sporadic metastatic pheochromocytoma and paraganglioma. Eur J Nucl Med Mol Imaging. 2016;43:1784-1791.

35. Lenders JW, Duh QY, Eisenhofer G, et al. Pheochromocytoma and paraganglioma: an Endocrine Society clinical practice guideline. J Clin Endocrinol Metab. 2014;99: 1915-1942.

36. Boellaard R, O'Doherty MJ, Weber WA, et al. FDG PET and PET/CT: EANM procedure guidelines for tumour pet imaging—version 1.0. Eur J Nucl Med Mol Imaging. 2010;37:181-200.

37. Kan Y, Zhang S, Wang W, Liu J, Yang J, Wang Z. ${ }^{68}$ Ga-somatostatin receptor analogs and ${ }^{18}$ F-FDG PET/CT in the localization of metastatic pheochromocytomas and paragangliomas with germline mutations: a meta-analysis. Acta Radiol. 2018;59: 1466-1474.

38. Nockel P, El Lakis M, Gaitanidis A, et al. Preoperative ${ }^{18}$ F-FDG PET/CT in pheochromocytomas and paragangliomas allows for precision surgery. Ann Surg. 2019; 269:741-747.

39. Cantalamessa A, Caobelli F, Paghera B, Caobelli A, Vavassori F. Role of ${ }^{18}$ F-FDG $\mathrm{PET} / \mathrm{CT},{ }^{123} \mathrm{I}$-MIBG SPECT, and CT in restaging patients affected by malignant pheochromocytoma. Nucl Med Mol Imaging. 2011;45:125-131.
40. Chang CA, Pattison DA, Tothill RW, et al. ${ }^{68}$ Ga-DOTATATE and ${ }^{18}$ F-FDG PET/CT in paraganglioma and pheochromocytoma: utility, patterns and heterogeneity. Cancer Imaging. 2016;16:22.

41. Denis A, Mirallie E, Dru D, Renaudin KA, Kraeber-Bodere F, Ansquer C. Contribution of ${ }^{18} \mathrm{~F}-\mathrm{FDG} \mathrm{PET} / \mathrm{CT}$ in preoperative evaluation of pheochromocytoma:comparison with MIBG scintigraphy [in French]. Médecine Nucléaire. 2018;42: $104-113$.

42. Zelinka T, Timmers HJ, Kozupa A, et al. Role of positron emission tomography and bone scintigraphy in the evaluation of bone involvement in metastatic pheochromocytoma and paraganglioma: specific implications for succinate dehydrogenase enzyme subunit B gene mutations. Endocr Relat Cancer. 2008;15:311-323.

43. Jha A, de Luna K, Balili CA, et al. Clinical, diagnostic, and treatment characteristics of SDHA-related metastatic pheochromocytoma and paraganglioma. Front Oncol. 2019;9:53.

44. Jha A, Ling A, Millo C, et al. Superiority of ${ }^{68}$ Ga-DOTATATE over ${ }^{18}$ F-FDG and anatomic imaging in the detection of succinate dehydrogenase mutation (SDHx)related pheochromocytoma and paraganglioma in the pediatric population. Eur $J$ Nucl Med Mol Imaging. 2018;45:787-797.

45. Leijon H, Remes S, Hagstrom J, et al. Variable somatostatin receptor subtype expression in 151 primary pheochromocytomas and paragangliomas. Hum Pathol. 2019;86: 66-75.

46. Reubi JC, Waser B, Khosla S, et al. In vitro and in vivo detection of somatostatin receptors in pheochromocytomas and paragangliomas. J Clin Endocrinol Metab. 1992;74:1082-1089.

47. Antunes P, Ginj M, Zhang H, et al. Are radiogallium-labelled DOTA-conjugated somatostatin analogues superior to those labelled with other radiometals? Eur J Nucl Med Mol Imaging. 2007;34:982-993.

48. Velikyan I, Sundin A, Sorensen J, et al. Quantitative and qualitative intrapatient comparison of ${ }^{68} \mathrm{Ga}$-DOTATOC and ${ }^{68} \mathrm{Ga}$-DOTATATE: net uptake rate for accurate quantification. J Nucl Med. 2014;55:204-210.

49. Gild ML, Naik N, Hoang J, et al. Role of DOTATATE-PET/CT in preoperative assessment of phaeochromocytoma and paragangliomas. Clin Endocrinol (Oxf). 2018;89:139-147.

50. Archier A, Varoquaux A, Garrigue P, et al. Prospective comparison of ${ }^{68}$ Ga-DOTATATE and ${ }^{18}$ F-FDOPA PET/CT in patients with various pheochromocytomas and paragangliomas with emphasis on sporadic cases. Eur J Nucl Med Mol Imaging. 2016;43:1248-1257.

51. Hofman MS, Lau WF, Hicks RJ. Somatostatin receptor imaging with ${ }^{68}$ Ga DOTATATE PET/CT: clinical utility, normal patterns, pearls, and pitfalls in interpretation. Radiographics. 2015;35:500-516.

52. Janssen I, Chen CC, Taieb D, et al. ${ }^{68} \mathrm{Ga}$-DOTATATE PET/CT in the localization of head and neck paragangliomas compared with other functional imaging modalities and CT/MRI. J Nucl Med. 2016;57:186-191.

53. Han S, Suh CH, Woo S, Kim YJ, Lee JJ. Performance of ${ }^{68}$ Ga-DOTA-conjugated somatostatin receptor-targeting peptide PET in detection of pheochromocytoma and paraganglioma: a systematic review and metaanalysis. $J$ Nucl Med. 2019;60: 369-376.

54. van der Harst E. $\left[{ }^{123} \mathrm{I}\right]$ metaiodobenzylguanidine and $\left[{ }^{111} \mathrm{In}\right]$ octreotide uptake in benign and malignant pheochromocytomas. J Clin Endocrinol Metab. 2001;86: 685-693.

55. Song JH, Chaudhry FS, Mayo-Smith WW. The incidental adrenal mass on CT: prevalence of adrenal disease in 1,049 consecutive adrenal masses in patients with no known malignancy. AJR. 2008;190:1163-1168.

56. Buitenwerf E, Korteweg T, Visser A, et al. Unenhanced CT imaging is highly sensitive to exclude pheochromocytoma: a multicenter study. Eur J Endocrinol. 2018;178: $431-437$.

57. Mohammed MF, ElBanna KY, Ferguson D, Harris A, Khosa F. Pheochromocytomas versus adenoma: role of venous phase CT enhancement. AJR. 2018;210: 1073-1078.

58. Schieda N, Alrashed A, Flood TA, Samji K, Shabana W, McInnes MD. Comparison of quantitative MRI and CT washout analysis for differentiation of adrenal pheochromocytoma from adrenal adenoma. AJR. 2016;206:1141-1148.

59. Tufton N, Sahdev A, Drake WM, Akker SA. Can subunit-specific phenotypes guide surveillance imaging decisions in asymptomatic SDH mutation carriers? Clin Endocrinol $(O x f)$. 2019;90:31-46.

60. Guichard JP, Fakhry N, Franc J, Herman P, Righini CA, Taieb D. Morphological and functional imaging of neck paragangliomas. Eur Ann Otorhinolaryngol Head Neck Dis. 2017;134:243-248.

61. Gravel G, Niccoli P, Rohmer V, et al. The value of a rapid contrast-enhanced angioMRI protocol in the detection of head and neck paragangliomas in SDHx mutations carriers: a retrospective study on behalf of the PGL.EVA investigators. Eur Radiol. 2016;26:1696-1704.

62. King KS, Chen CC, Alexopoulos DK, et al. Functional imaging of SDHx-related head and neck paragangliomas: comparison of ${ }^{18} \mathrm{~F}$-fluorodihydroxyphenylalanine, ${ }^{18} \mathrm{~F}$ - 
fluorodopamine, ${ }^{18} \mathrm{~F}$-fluoro-2-deoxy-D-glucose PET, ${ }^{123} \mathrm{I}$-metaiodobenzylguanidine scintigraphy, and ${ }^{111}$ In-pentetreotide scintigraphy. J Clin Endocrinol Metab. 2011; 96:2779-2785.

63. Hoegerle S, Ghanem N, Altehoefer C, et al. ${ }^{18} \mathrm{~F}$-DOPA positron emission tomography for the detection of glomus tumours. Eur J Nucl Med Mol Imaging. 2003;30: 689-694.

64. Blanchet EM, Gabriel S, Martucci V, et al. ${ }^{18}$ F-FDG PET/CT as a predictor of hereditary head and neck paragangliomas. Eur J Clin Invest. 2014;44:325-332.

65. Waguespack SG, Rich T, Grubbs E, et al. A current review of the etiology, diagnosis, and treatment of pediatric pheochromocytoma and paraganglioma. JClin Endocrinol Metab. 2010;95:2023-2037.

66. Neumann HP, Bausch B, McWhinney SR, et al. Germ-line mutations in nonsyndromic pheochromocytoma. N Engl J Med. 2002;346:1459-1466.
67. Khafagi FA, Shapiro B, Fischer M, Sisson JC, Hutchinson R, Beierwaltes WH. Phaeochromocytoma and functioning paraganglioma in childhood and adolescence: role of iodine 131 metaiodobenzylguanidine. Eur J Nucl Med. 1991;18:191-198.

68. Babic B, Patel D, Aufforth R, et al. Pediatric patients with pheochromocytoma and paraganglioma should have routine preoperative genetic testing for common susceptibility genes in addition to imaging to detect extra-adrenal and metastatic tumors. Surgery. 2017;161:220-227.

69. Lumachi F, Tregnaghi A, Zucchetta P, et al. Sensitivity and positive predictive value of CT, MRI and ${ }^{123}$ I-MIBG scintigraphy in localizing pheochromocytomas: a prospective study. Nucl Med Commun. 2006;27:583-587.

70. Cerdan F, Gabriel S, Sebag F, et al. Functional assessment of non-metastatic paraganglioma and pheochromocytoma by ${ }^{18}$ F-FDOPA PET: impact of tumor localization and genetic status [in French]. Médecine Nucléaire. 2013;37:116-123. 